\title{
Thought on Propelling the Construction of Social Security System for Migrant Worker Group
}

\author{
Jiemei Li \\ Law and Business, School, Wuhan Institute of Technology, Wuhan Hubei, 430205, China
}

Keywords: Migrant worker, Social security, System construction.

\begin{abstract}
With the continuous development of urbanization process, abundant surplus laborers in China's rural areas transfer to non-agricultural industries, so there are numerous issues in the social security system. Regardless of all sorts of social security systems enacted by the country, migrant workers, who are marginal people of city, have a very low possibility to enjoy social security; thus, it is one of the important problems in the current social development process to deeply think the migrant workers' social security issue. This paper discusses the current situation of the construction of social security system for China's migrant worker group and the migrant workers' major social security risks in our country, analyzes the problems in the construction of social security system for the migrant worker group, and puts forward the countermeasures to further propel the construction of social security system for migrant workers.
\end{abstract}

\section{Introduction}

The continuous development of China’s economic society and the sustained enhancement of people’s living standard have led to the increasingly perfect social security system in our country. In particular, as the speed of industrialization and urbanization is quickened continuously after the reform and opening-up, an increasing number of rural laborers work in cities, resulting in a large scale of migrant worker group to promote the new development of China's economic society. Because of economic development, migrant workers have their life, work and many other aspects improved greatly and also have their income enhanced. However, meanwhile, there is no good social security system for their survival. For this reason, it is required to deeply explore the problem of construction of social security system for migrant workers.

\section{Current situation of construction of social security system for migrant workers in China}

The reform and opening-up policy has resulted in that an increasing number of surplus laborers in rural areas go to cities to form the migrant worker group. So far, the number of migrant workers in China has reached up to 230,000,000 persons and is ceaselessly growing every year. Different from both the peasants in the traditional sense and the urban workers, migrant workers are a group with special identity created under China's traditional household registration system. Although migrant workers play important roles in China's urbanization and make huge contributions to the economic development, the current overall social security condition of migrant workers of China is not optimistic. They have not only an extremely low rate of joining insurance but also a continuously high surrender rate in social security. As a result, migrant workers are always separated from the rural social security system in their working process and face the dangerous situation of a lack of security in work. Once they face a difficult situation, an extremely severe hidden danger may be caused to the social stability due to their lack of social security and social relief.

\section{Main social security risks China's migrant workers face}

As a mandatory national income transferring payment mechanism, social security provides safety protection mainly through the individual risk loss of economic resources. Compared with the 
agricultural society in the traditional sense, the migrant workers under the employment system in the modern industrial society are more likely to suffer losses in the fierce social competition, because peasants cannot obtain a good guarantee from their area occupied per capita despite the protection of land and the non-agricultural job market is also risky. Therefore, the social security problem of migrant workers becomes more important. The income risk of migrant workers contains two aspects: firstly, the insufficient stock of peasant human capital limits the enhancement of migrant workers' income level; secondly, there is no reasonable wage income growth system. As for migrant workers' income risk, it is mainly because the majority of the migrant workers with a low overall human capital level are engaged in work with very low technical content and even some work without any technical content. Due to their low degree of education, they mainly get engaged in the labor-intensive work needing physical labor and low technical requirements, largely limiting the increase in their wage income level. Meanwhile, the migrant worker group is always in a weak position in contractual labor relationship and it is very difficult for migrant workers to maintain their legitimate rights and interests, so they lack adequate strength to raise their overall income level. Besides, migrant workers' rights and interests maintenance is characterized by high mobility, so the organization degree of migrant workers is very low and thus it is difficult to create a collective payment negotiation mechanism and a labor force balance system.

\section{Problems in the construction of social security for migrant worker group}

Firstly, the setting of social insurance system is not reasonable. At present, China's urban social insurance lacks sufficient flexibility and rationality due to its high starting point. Besides, China's migrant worker group usually involves the practical conditions such as high mobility, low living standard and low overall cultural quality. As specified in relevant documents, in order to make migrant workers to enjoy social security, not only migrant workers shall bear part of insurance expense but also their employers must assume some expenses; however, for many enterprises without enough strength, taking the responsibility of paying the expenses on social security of migrant workers means the increase in their production cost; in addition, spending part of migrant workers' limited income in paying the social security expenses will directly reduce their current income. In this way, both the migrant workers and enterprises consider the insurance expenses as an excessively heavy burden and don't want to bear such an expense, so it is inevitable that the both sides' initiative in joining insurance will be lowered. Furthermore, the difficulty in transferring a social insurance relationship results in the difficulty in practical and effective implementation of medical security and other social security systems. Meanwhile, due to the not unified policies in all regions caused by the great difference in the development of all provinces and regions in China and the deficiencies in the design of social security system, it is difficult to accumulate the migrant worker group's years of social insurance and the procedure for transfer and renewing is also very complicated, so abundant human and material resources are likely to be consumed. In addition, free surrender, which can be regarded as a great drawback of China's current endowment insurance policy, will cause the constant emergence of repeated participation in insurance and surrender, increasing the workload of the social security department and greatly damaging the migrant worker group's interests. As per the current rules and regulations, only the part of insurance expense paid by individuals can be returned and the part paid by the employers is used by the government to fill up the social security fund gap. Therefore, it largely infringes the social security rights and interests that the migrant worker group should enjoy.

Secondly, the arrangements of some social security systems fail to comply with the employment characteristics of China migrant worker group. The types of industries and specialties involved by the migrant workers who have realized informal employment are very complicated, including waiter, security guard, babysitter, plumber, household maintenance personnel, cleaning staff, greening worker, healthcare worker, other social service personnel as well as the interim workers in enterprise and public institutions. It is exactly the extreme complicity in personnel structure and the lack of 
fixed connection that lead to the high mobility of migrant workers. Therefore, it is extremely difficult to find out their basic information, such as insurance information.

Thirdly, the social security of China's migrant worker group lacks good law and regulation protection. As the identity of China's migrant workers has not been clearly recognized in cities, it is hard to equally provide them with the relevant social security system which is applicable to the urban residents, let alone provide them with sufficient law protection. In this way, the migrant worker group's interests and rights cannot be practically safeguarded. In view of the usually limited coverage of social security system for migrant workers and the relatively low level of overall social planning, it is required to expressly specify the legal status of migrant workers in the form of laws and regulations during the targeted implementation of social security system for migrant worker group, so as to ensure the expansion of coverage of social security for migrant workers as well as the efficacy and execution of laws and regulations which enhance the level of overall social planning of social security for migrant workers.

\section{Countermeasures to further promote the construction of social security system for migrant worker group}

\section{Ceaselessly improve all social security systems for migrant worker group}

Firstly, continuously improve the work-related injury insurance mechanism for migrant workers. According to the relevant provision in Regulations on Work-Related Injury Insurances, all China's employers shall buy the work-related insurance for the migrant worker group so that they can get the corresponding compensations for work-related injuries and occupational diseases etc. The governmental department concerned shall supervise this with all its strength, make mandatory provisions and requirements on employers with the authority of governmental department, and guide employers to perform related duties. The governmental department shall strictly punish an enterprise or public institution which fails to fulfill related duties. On this basis, the governmental department should further enhance the prevention of work-related injuries, formulate a work-related injury prevention system suitable for China's practical condition, and spare no effort to prevent and curb the occurrence of any work-related injury and occupational disease. Secondly, work on improving the mechanism of medical insurance against critical illness for migrant worker group. Improving the mechanism aims to enhance the medical security ability. It is especially important to establish the mechanism in the industries with some dangerous factors. For instance, with a high danger and high pollution, the construction industry may cause great threats to the migrant worker group's health. To provide the migrant worker group with more comprehensive health protection, they can not only join the new rural cooperative medical insurance but also the medical insurance against critical illness for migrant workers synchronously. It is required to reasonably lower the threshold and adjust individuals' payment proportion, hospitalization deposit and other policies concerned in medical insurance based on the specific condition of migrant worker group, so as to better meet the practical need of China's migrant worker group and practically alleviate their burden; constantly expand the scope of medical security service so that it can serve the health of the migrant worker group in a better way. Thirdly, put the transitional endowment insurance mechanism into practice. The author found, during the investigation, that the migrant workers' work mobility is generally high, so the personal account accumulation system can be implemented for the group; both employers and migrant workers should pay the expenses for endowment insurance respectively with the total amount paid to be possessed by individuals, who can make real-time queries for the amount.

\section{Practically reform the existing household registration system to eliminate the "identity barrier" between urban and rural residents}

The social structure with urban-rural opposition centering on the household registration system is the fundamental factor causing the imperfect construction of China's social security system for migrant 
workers. Therefore, in order to further improve the social security system for migrant worker group, legally safeguard all legitimate rights and interests of migrant worker group and thus realize the goal of common prosperity, it is required to practically improve the current household registration system, gradually remove all barriers between urban and rural areas so that the migrant worker group can obtain the same social status and right of survival and development like urban residents, and can enjoy the same right to social security. For this purpose, it is required to take practical actions to get rid of difference between agricultural household and non-agricultural household causing urban and rural segmentation and truly break the long-term system of "household determining identity". Later, create a completely unified new household registration management system nationwide and facilitate the dynamic management over population by improving the individual identity system.

\section{Expressly specify the legal responsibilities of all parties in the social security system for migrant workers}

To fully carry out the social security mechanism of urban-rural integration, it is required to constantly improve the laws and regulations concerned and specify the social security status of migrant worker group more expressly so that the social security system for migrant workers in cities can be more operable and can practically help the migrant worker group to better safeguard their own interests and rights of social security; besides, fully supervise and urge employers to actively pay expenses regarding social security for migrant worker group and give full play to the functions of the migrant workers' social security mechanism and supervision system. Of course, it is also required to work on creating the social security network system for migrant workers and fully promote the nationwide mobility, connection and transfer of social security for migrant workers. The government should fully lead to form a more steady social security fund preparation system with the responsibilities shared by enterprises, individual, the state and all related parties, and clearly stipulate the responsibilities borne by the state, enterprises and migrant workers at the level of laws and regulations. All parties should take their respective responsibilities for the payment of their own expenses for social insurance.

\section{Improve the social security management system for migrant workers}

An important measure to propel the construction of social security system for migrant worker group is to practically raise the management level of social security work for migrant workers. Firstly, in consideration of the frequent job mobility of migrant workers, the state should set up a special organization among the departments concerned to take charge of matters concerning social security of migrant workers, take a series of measures to improve the social security system for migrant worker group, continuously enhance the management ability in working practice and pay adequate attention to management. Secondly, from the perspective of social security fund, the state must pay high attention to the overall management over social security fund and, especially, pay special attention to the raising of social security fund and the payment of all related fees. Strictly control the expenditures of social security fund and guarantee that every penny is effectively spent in safeguarding the interests of people, including migrant workers. An independent operation mechanism of social insurance for migrant worker group can be put into trial use in some developed regions where many migrant workers buy social insurance; besides, strengthen the management over capital investment and operation etc. during this process so that value preservation and appreciation can be truly achieved.

\section{Conclusion}

To sum up, it can be found from the study on the construction of social security system for migrant worker group that the migrant workers facilitate the sustainable development of cities via their hard work in the course of continuous development of urbanization. However, the migrant workers haven't completely enjoyed the social security that the urban residents enjoy and neither social equality nor justice has been embodied well. In view of this, the governmental department must 
actively construct the social security system which can practically meet the actual rights and interests of migrant worker group so as to realize the goals of improving people's livelihood and promoting the social progress. The active construction of social security system for migrant worker group can help better eliminate the urban-rural opposition and create better conditions for the free mobility of migrant workers.

\section{Acknowledgments}

This paper is a planned project of soft science of Science and Technology Agency of Hubei Province. 1). Study on Government's Responsibility Boundary in the Construction of New Social Security System in Rural Areas (Project No.: 2010DHA016); 2). Investigation and Analysis on Economic and Social Effects of Trial Implementation of "House-For-Pension Scheme" - Taking Wuhan for Example (2014BKF139);

\section{References}

[1] Xu Jie, Gao Jun and Xia Lixia. Exploration on the Problem of Social Security for Migrant Workers in Cities on the Background of Overall Urban-rural Background. Research of Agricultural Modernization, 2012 (1).

[2] Jia Shuming. Study on the Problem of Social Security of Migrant Workers. Journal of Journal of Shandong Agricultural Administrators' College, 2012 (2).

[3] Yang Wendong and Yin Li. Some Thoughts on Social Security System for Migrant Workers. Legal System and Society, 2012 (3).

[4] Zhu Jinfang. Reform and Innovation of Social Security System for Migrant Workers under Perspective of Citizenization. Anhui Agricultural Sciences, 2012 (6).

[5] Hang Dongting. Study on Problems in China's Social Security System for Migrant Workers and Countermeasures. Agricultural Economics, 2013 (6).

[6] Wang Shuhong. Study on Problems in Social Security of Migrant Workers in Cities and Countermeasures. Science-Technology Enterprise, 2014 (12). 